
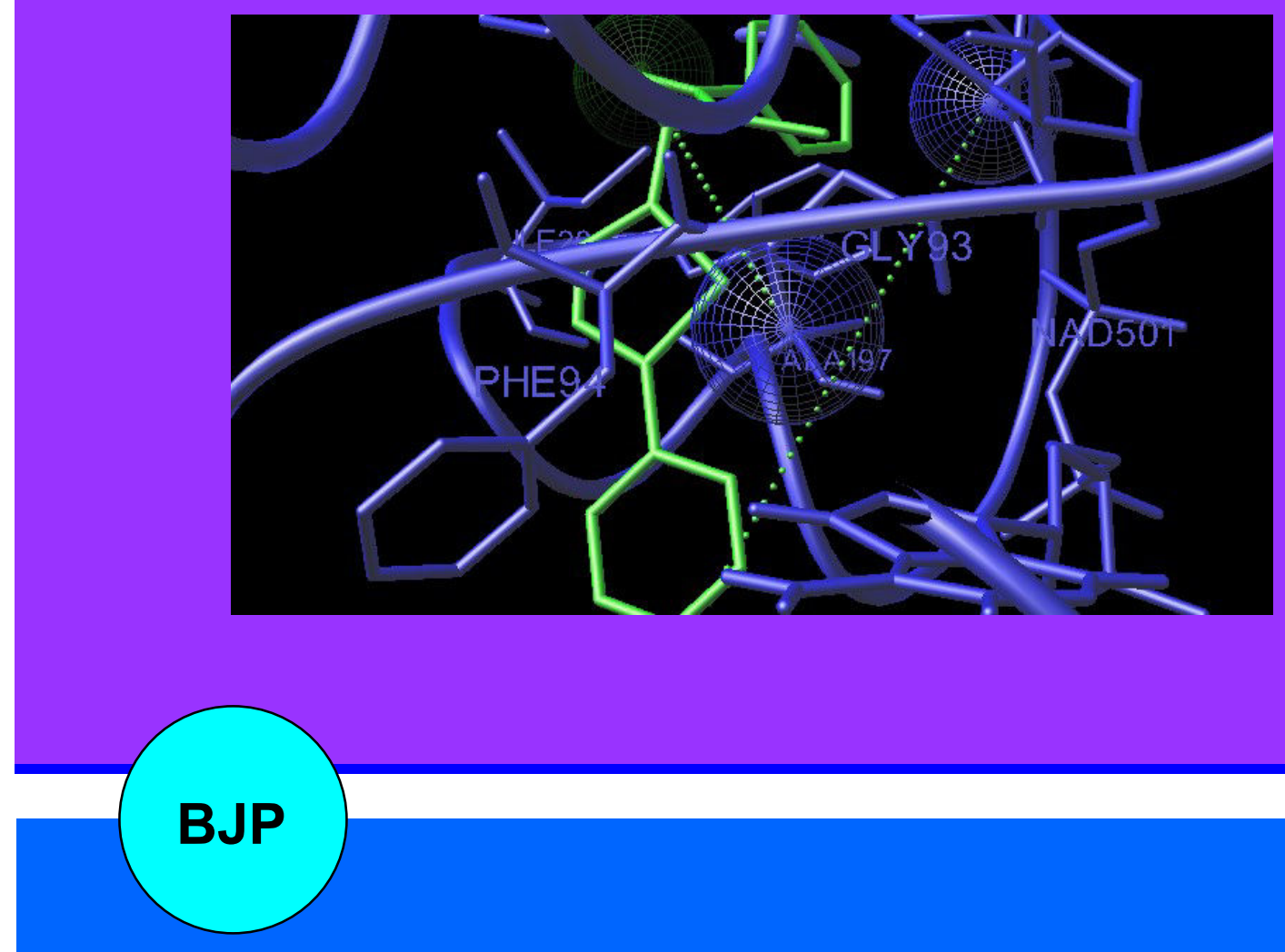

Bangladesh Journal of Pharmacology

Research Article

Design, docking, synthesis and anti E. coli screening of novel thiadiazolo thiourea derivatives as possible inhibitors of Enoyl ACP reductase 


\title{
Design, docking, synthesis and anti E. coli screening of novel thiadiazolo thiourea derivatives as possible inhibitors of Enoyl ACP reductase (Fabl) enzyme
}

\author{
Sonia George, Ramzeena Mohammed Basheer, Sayee Vignesh Ram, Senthil Kumar Selvaraj, Shinu \\ Rajan and Thengungal Kochupappy Ravi
}

Department of Pharmaceutical Chemistry, College of Pharmacy, Sri Ramakrishna Institute of Paramedical Sciences, Coimbatore, Tamilnadu, India

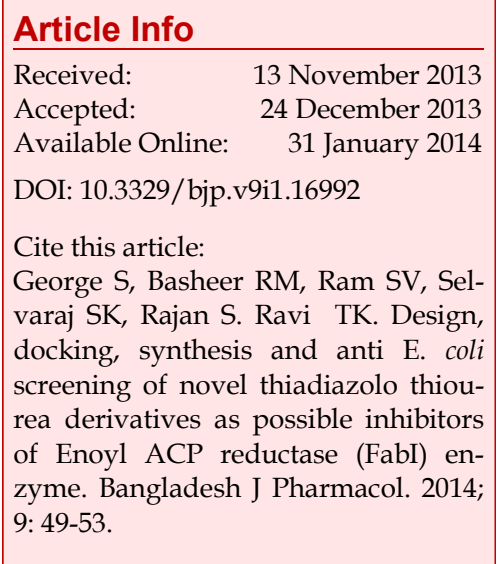

\section{Abstract}

A series of 1-phenyl-[5-substitutedphenyl)-1,3,4-thiadiazol-2-yl]-3-thiourea (3a-h) were synthesized and screened for their anti Escherichia coli potential. The characterization of the newly synthesized compounds was based upon their spectral data. The design of the title compounds was done utilizing the in silico methodology. Virtual screening technique was utilized for the identification of the lead, thiadiazole. The pharmacokinetic behavior was predicted by lead optimization and docking studies helped to analyze the binding interactions. Antibacterial activity of the title compounds were predicted by the PASS prediction software. The anti E. coli screening results showed that the derivatives, $3 \mathbf{b}$ and $\mathbf{3 h}$ possessed significant activity.

\section{Introduction}

The major drawback in the antimicrobial drug therapy is the resistance offered by the microbes even to the established entities. These shortcomings are owing to the mutations associated, noncompliance in the drug therapy etc. The discovery of new drugs is now focussed on drug targets like enzymes or receptors. FabI, the enoyl acyl carrier protein reductase of the Escherichia coli species is one of the attractive targets in E. coli associated diseases (Helmut et al., 1994). Enoyl ACP reductase is involved in the elongation of fatty acid which serves as the precursor for mycolic acid biosynthesis (Richard et al., 1995).

The biocidal activity possessed by triclosan is identified recently due to its interactions with the enoyl ACP reductase (Roujeinikova et al., 1999). Other moieties like oxadiazoles, thiadiazoles, pyrazoles etc are also reported to possess inhibition of this enzyme target (Sonia et al., 2012; Sonia et al., 2011; Kuo et al., 2003). Thiourea derivatives are reported to possess excellent antibacterial potential (Arslan et al., 2009). Owing to the above facts and in continuation of the research on enoyl ACP reductase inhibitors, an attempt is made in the present research to design and develop new anti E. coli agents possessing enoyl ACP reductase inhibition. The antibac -terial effect of the incorporation of phenyl thiourea to the thiadiazoles was predicted by the PASS computational approach.

\section{Materials and methods}

Melting points were determined by using melting point apparatus MR-VIS (MR08190508). IR spectra were recorded on JASCO FT/IR-410 spectrometer on $\mathrm{KBr}$ pellets. ${ }^{1} \mathrm{HNMR}$ and ${ }^{13} \mathrm{C}$ NMR spectra were recorded on a Bruker $300 \mathrm{MHz}$ NMR spectrometer. Mass spectra data was obtained from Shimadzu, LCMS 2010 EV. Purity of all the compounds were checked by thin layer chromatography using silica gel-G as adsorbent and 
iodine vapour as detecting agent. The softwares used for in silico works were iGEMDOCK v.2, Accelerys Accord for Excel and AutoDock4.2.

Virtual Screening: Virtual screening technique is utilized for the selection of target and the ligand. Virtual screening was performed utilizing iGEMDOCK v.2 (http: //gemdock.life.nctu.edu.tw/ dock/). The hits were selected from the ZINC database (http:// zinc.docking.org/), a database of thirteen million compounds in purchasable format.

Selection of the target and lead: The target enzyme selected was enoyl-acyl protein reductase (FabI) and the hits were obtained from the zinc database. The selection of lead from the hits was based on the virtual screening technique using iGEMDOCK v.2. A small molecular library of 10,000 hits was constructed utilizing ZINC database and was docked into the enzyme and the potential leads were discovered based on the binding affinity. Thiadiazole was selected as the potential lead.

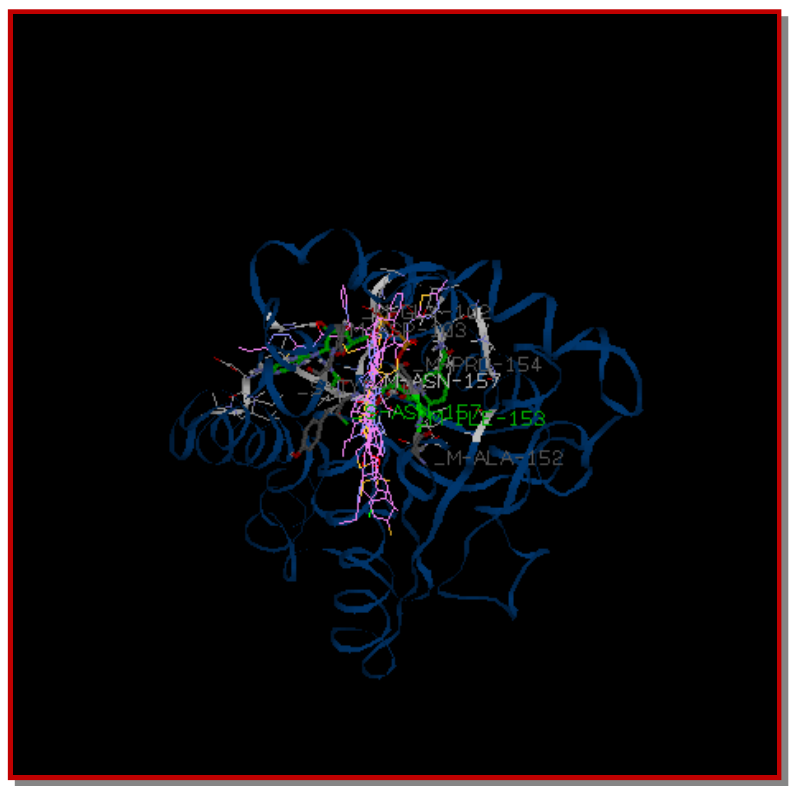

Figure 1: Binding alignment of thiadiazole moieties with the enzyme in virtual screening
The binding alignment of the selected moiety is depicted in Figure 1.

Lead optimization: The selected lead was substituted with various substituent and the in silico lead optimization was done to evaluate its pharmacokinetic profile (Table I). The optimization of the lead was done utilizing Accelerys Accord for Excel (Accelerys Software Inc., San Diego).

Molecular docking studies: AutoDock4.2 was the software used for docking (http://autodock. scripps.edu/).

Enzyme and ligand preparation: The X-ray crystal structure of the enzyme enoyl ACP reductase (FabI) of E. coli (PDB entry: 1C14) was obtained from Protein Data Bank (http://www.rcsb.pdb.org). The enzyme was refined to remove the hetero atoms and water and Kollmann charges were added. The optimized ligand structures were energy minimized, Gasteiger charges and polar hydrogens were added and torsion was set.

Docking simulations: The energy minimized ligands were subjected to docking studies in order to predict its interaction with the key binding sites on the enzyme. Initially Grid map was set with 60 points and a spacing of $0.375 \mathrm{~A}^{\circ}$ was set. Lamarckian genetic algorithm was used, with a maximum number of 25,000,000 energy evaluations and a maximum number of 5,000 generations, for each run and 150 docking runs were performed. The binding energies obtained through in silico studies are depicted in Table I. The snap shots of the docked structures are shown in Figure 2.

PASS prediction: PASS prediction is based on SAR analysis of the training set containing more than 35,000 compounds which have more than 500 kinds of biological activity. This in silico method is used to predict the activity of the chemical entity before its synthesis. The compounds subjected to docking studies in the present study were subjected to PASS prediction to confirm its potential as anti E. coli agents. If $\mathrm{Pa}>0.7$ the chance to find the activity in experiment is high, but in many cases the compound may occur to be the close analogue of known pharmaceutical agents. If

\begin{tabular}{|c|c|c|c|c|c|c|c|c|}
\hline \multicolumn{9}{|c|}{ Table I } \\
\hline \multicolumn{9}{|c|}{ Data of in silico screening } \\
\hline \multirow{2}{*}{$\begin{array}{l}\text { SL } \\
\text { No. }\end{array}$} & \multirow{2}{*}{$\begin{array}{l}\text { Compound } \\
\text { code }\end{array}$} & \multicolumn{4}{|c|}{ Pharmacokinetic parameters } & \multicolumn{2}{|c|}{ PASS prediction } & \multirow{2}{*}{$\begin{array}{c}\text { Docking parameters } \\
\qquad \Delta \mathrm{G}(\mathrm{kcal} / \mathrm{mol})\end{array}$} \\
\hline & & $\operatorname{mLog} p$ & HIA & PBL & HTL & $\mathrm{Pa}$ & $\mathrm{Pi}$ & \\
\hline 1 & $3 a$ & 4.321 & 1 & 3 & 0 & 0.710 & 0.004 & -7.34 \\
\hline 2 & $3 b$ & 3.987 & 1 & 4 & 0 & 0.790 & 0.004 & -8.33 \\
\hline 3 & $3 c$ & 4.324 & 1 & 3 & 0 & 0.687 & 0.004 & -7.48 \\
\hline 4 & $3 d$ & 4.562 & 1 & 4 & 0 & 0.667 & 0.004 & -7.56 \\
\hline 5 & $3 e$ & 4.128 & 1 & 4 & 0 & 0.742 & 0.003 & -6.23 \\
\hline 6 & $3 f$ & 4.387 & 1 & 2 & 0 & 0.674 & 0.003 & -7.46 \\
\hline 7 & $3 g$ & 3.888 & 1 & 4 & 0 & 0.732 & 0.003 & -7.01 \\
\hline 8 & $3 \mathrm{~h}$ & 4.012 & 1 & 3 & 0 & 0.810 & 0.003 & -8.74 \\
\hline 9 & Triclosan & - & - & - & - & - & - & -6.78 \\
\hline
\end{tabular}


$0.5<\mathrm{Pa}<0.7$ the chance to find the activity in experiment is less, but the compound is not so similar to known pharmaceutical agents. If $\mathrm{Pa}<0.5$ the chance to find the activity is even more less, but it can be also a New Chemical Entity (Poroikov et al., 2002). The PASS prediction data is given in Table I.

Synthesis of 2-amino-5substituted phenyl) -1, 3, 4thiadiazole $(2 a-h)$ : 2-amino-5-substituted phenyl-1,3,4thiadiazole $(2 a-h)$ were synthesized based on the reported procedure (Jatav et al., 2008).

Synthesis of 1phenyl-[5-substitutedphenyl)-1,3,4-thiadiazol2-yl]-3-thiourea (3a-h): A mixture of 2-amino-5substitutedphenyl-1,3,4-thiadiazole $2 a \quad(0.001 \mathrm{M})$, phenyl isothiocyanate $(0.001 \mathrm{M})$ in ethanolic $\mathrm{KOH}(1 \mathrm{~N}$, $3 \mathrm{~mL}$ ) was refluxed for 2 hours and the reaction mixture was poured into ice-cold water. The solid separated was filtered and recrystallised from ethanol. The other thiadiazolyl thioureas were prepared in the same way. The completion of the reaction was monitored using solvent system (acetone/benzene: 4:6).

1-phenyl-3-(5-phenyl-1,3,4-thiadiazol-2-yl)thiourea (3a): M.p: $141.2^{\circ} \mathrm{C}$; Rf: 0.65; IR: (KBr, vmax / $\left.\mathrm{cm}^{-1}\right)$ : 3262.134 $(\mathrm{NH}), 2345.61$ (Aromatic C-H), 1591.32 (Thiadiazole $\mathrm{C}=\mathrm{N}), 1519.34$ (RingC=C), 831.29 (Thiadiazole C-S); ${ }^{1} \mathrm{H}$ NMR (300 MHz, DMSO-d6, Sppm): 10.732 (bs, 1H, Ph$\mathrm{NH}), 9.112$ (bs, 1H, C-NH), 7.324-7.842 (m, 10H, Ar-H),; ${ }^{13} \mathrm{C}$ NMR (300 MHz, DMSO-d6, oppm): 58.765, 121.234127.324 (Aromatic carbons), 162.375 ( $\mathrm{C}_{2}$ of thiadiazole), 172.310 ( $\mathrm{C}_{5}$ of thiadiazole); MS: $\mathrm{m} / \mathrm{z}(\mathrm{M}+)^{+}+312$.

1-[5-(4-chlorophenyl)-1,3,4-thiadiazol-2-yl]-3-phenylthiourea (3b): M.p: $251.9^{\circ} \mathrm{C}$; Rf: 0.65; IR: (KBr, $\left.v \max / \mathrm{cm}^{-1}\right)$ : $3263.93(\mathrm{NH}), 2361.41$ (aromatic C-H), 1593.88 (thiadiazole $\mathrm{C}=\mathrm{N}$ ), 1512.88 (ring $\mathrm{C}=\mathrm{C}$ ), 829.241 (thiadiazole C-S); ${ }^{1} \mathrm{H}$ NMR (300 MHz, DMSO-d6, Sppm): 10.491(bs, 1H, Ph-NH), 9.241 (bs, 1H, C-NH), 7.653-7.936 (m, 9H, Ar-H); ${ }^{13} \mathrm{C}$ NMR (300 MHz, DMSOd6, Jppm): 56.477, 122.497-129.356 (aromatic carbons), 161.251 ( $\mathrm{C}_{2}$ of thiadiazole), 171.491 ( $\mathrm{C}_{5}$ of thiadiazole); MS: $\mathrm{m} / \mathrm{z}(\mathrm{M}+)^{+} 346$.

1-[5-(4-flurophenyl)-1,3,4-thiadiazol-2-yl]-3-phenylthiourea (3c): M.p: $72.8^{\circ} \mathrm{C}$; Rf: 0.69; IR: $\left(\mathrm{KBr}, v \mathrm{max} / \mathrm{cm}^{-1}\right)$ : 3269.33 $(\mathrm{NH}), 2364.11$ (aromatic C-H), 1588.91 (thiadiazole $\mathrm{C}=\mathrm{N}$ ), 1518.76 (ring $\mathrm{C}=\mathrm{C}$ ), 832.92 (thiadiazole C-S); ${ }^{1} \mathrm{H}$ NMR (300 MHz, DMSO-d6, oppm): 9.985 (bs, 1H, Ph$\mathrm{NH}), 9.123$ (bs, 1H, C-NH), 7.324-7.689 (m, 9H, Ar-H),; ${ }^{13} \mathrm{C}$ NMR (300 MHz, DMSO-d6, Sppm): 57.654, 118.534128.909 (aromatic carbons), 161.670 ( $\mathrm{C}_{2}$ of thiadiazole), 172.108 ( $\mathrm{C}_{5}$ of thiadiazole); MS: $\mathrm{m} / \mathrm{z}(\mathrm{M}+)^{+}+330$.

1-[5-(4-methoxyphenyl)-1,3,4-thiadiazol-2-yl]-3phenylthiourea (3d): M.p:145.3 ${ }^{\circ} \mathrm{C}$; Rf: 0.65; IR: $(\mathrm{KBr}$, vmax / $\left.\mathrm{cm}^{-1}\right): 3192.79(\mathrm{NH}), 2342.35$ (aromatic C-H), 1598.12 (thiadiazole $\mathrm{C}=\mathrm{N}$ ), 1512.23 (ring $\mathrm{C}=\mathrm{C}$ ), 831.34 (thiadiazole C-S); ${ }^{1} \mathrm{H}$ NMR $(300 \mathrm{MHz}, \mathrm{DMSO}-\mathrm{d} 6$, Sppm): 10.552 (bs, 1H, Ph-NH), 9.323 (bs, 1H, C-NH), 7.342-7.764 (m, 9H, Ar-H), 3.73 (s, 3H, $\left.\mathrm{OCH}_{3}\right) ;{ }^{13} \mathrm{C}$ NMR (300 MHz, DMSO-d6, סppm): 54.223, 123.245-129.064 (aromatic carbons), 160.251 ( $\mathrm{C}_{2}$ of thiadiazole), 170.231
( $\mathrm{C}_{5}$ of thiadiazole); MS: $\mathrm{m} / \mathrm{z}(\mathrm{M}+)^{+}+342$.

1-[5-(2,3,4-trimethoxyphenyl)-1,3,4-thiadiazol-2-yl]-3phenylthiourea (3e): M.p:243. $3^{\circ} \mathrm{C}$; Rf: 0.72; IR: $(\mathrm{KBr}$, vmax / $\left.\mathrm{cm}^{-1}\right)$ : $3242.31(\mathrm{NH}), 2342.53$ (aromatic C-H), 1591.23 (thiadiazole $\mathrm{C}=\mathrm{N}$ ), 1510.23 (ring $\mathrm{C}=\mathrm{C}$ ), 830.29 (thiadiazole C-S); ${ }^{1} \mathrm{H}$ NMR $(300 \mathrm{MHz}, \mathrm{DMSO}-\mathrm{d} 6$, Sppm): 10.556 (bs, 1H, Ph-NH), 9.341 (bs, 1H, C-NH), 7.324-7.845 (m, 7H, Ar-H), $3.681\left(\mathrm{~s}, 9 \mathrm{H},\left(\mathrm{CH}_{3}\right)_{3}\right) ;{ }^{13} \mathrm{C}$ NMR (300 MHz, DMSO-d6, Sppm): 55.232, 120.654126.670 (aromatic carbons), 161.411 ( $\mathrm{C}_{2}$ of thiadiazole), 170.371 ( $\mathrm{C}_{5}$ of thiadiazole); MS: $\mathrm{m} / \mathrm{z}(\mathrm{M}+)^{+} 402$.

1-\{5-[4-(propan-2-yl)phenyl]-1,3,4-thiadiazol-2-yl\}-3phenylthiourea (3f): M.p: $125.1^{\circ} \mathrm{C}$; Rf: 0.83; IR: (KBr, vmax / $\left.\mathrm{cm}^{-1}\right)$ : $3270.54(\mathrm{NH}), 2358.70$ (aromatic C-H), 1590.93 (thiadiazole $\mathrm{C}=\mathrm{N}$ ), 1510.28 (ring $\mathrm{C}=\mathrm{C}$ ), 831.24 (thiadiazole C-S); ${ }^{1} \mathrm{H}$ NMR (300 MHz, DMSO-d6, Sppm): 9.849 (bs, 1H, Ph-NH), 9.112 (bs, 1H, C-NH), 7.324-7.721 (m, 9H, Ar-H), 5.123 (s, 1H, CH), 3.231 (s, $\left.3 \mathrm{H}, \mathrm{CH}_{3}\right), 2.68\left(\mathrm{~s}, 3 \mathrm{H}, \mathrm{CH}_{3}\right) ;{ }^{13} \mathrm{C} \mathrm{NMR}(300 \mathrm{MHz}, \mathrm{DMSO}$ -d6, Sppm): $38.881 \quad\left(\mathrm{CH}_{3}\right), \quad 55.238, \quad 118.22-124.865$ (aromatic carbons), 162.371 ( $\mathrm{C}_{2}$ of thiadiazole), 170.322 ( $\mathrm{C}_{5}$ of thiadiazole); MS: $\mathrm{m} / \mathrm{z}(\mathrm{M}+)^{+}+355$.

1-[5-(4-hydroxyphenyl)-1,3,4-thiadiazol-2-yl]-3phenylthiourea (3g): M.p: $78.1^{\circ} \mathrm{C}$; Rf: 0.86; IR: (KBr, vmax / $\left.\mathrm{cm}^{-1}\right): 3320.45(\mathrm{OH}), 3270.25(\mathrm{NH}), 2342.25$ (aromatic C-H), 1586.21 (thiadiazole $\mathrm{C}=\mathrm{N}$ ), 1514.88 (ring $\mathrm{C}=\mathrm{C}), 842.12$ (thiadiazole C-S); ${ }^{1} \mathrm{H}$ NMR $(300 \mathrm{MHz}$,

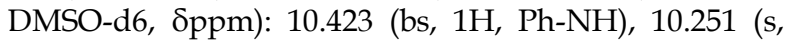
$1 \mathrm{H}, \mathrm{OH}), 9.371$ (bs, 1H, C-NH), 7.526-7.632 (m, 10H, Ar$\mathrm{H}) ;{ }^{13} \mathrm{C}$ NMR (300 MHz, DMSO-d6, Sppm): 57.486, 122.666-128.569 (aromatic carbons), $162.354 \quad\left(\mathrm{C}_{2}\right.$ of thiadiazole), 172.354 ( $\mathrm{C}_{5}$ of thiadiazole); MS: $\mathrm{m} / \mathrm{z}(\mathrm{M}+)$ +329 .

1-[5-(3-nitrophenyl)-1,3,4-thiadiazol-2-yl]-3-phenylthiourea (3h): M.p: $204.4^{\circ} \mathrm{C}$; Rf: 0.75; IR: (KBr, $\left.v \max / \mathrm{cm}^{-1}\right)$ : $3260.39(\mathrm{NH}), \quad 2358.42$ (aromatic C-H), 1591.25 (thiadiazole $\mathrm{C}=\mathrm{N}$ ), $1515.36 \quad$ (ring $\mathrm{C}=\mathrm{C}$ ), 835.14 (thiadiazole C-S); ${ }^{1} \mathrm{H}$ NMR (300 MHz, DMSO-d6, Sppm): 10.520 (bs, 1H, Ph-NH), 9.352 (bs, 1H, C-NH), 7.342-7.736 (m, 9H, Ar-H); ${ }^{13} \mathrm{C}$ NMR (300 MHz, DMSOd6, Sppm): 54.231, 118.452-125.875 (aromatic carbons), 160.235 ( $\mathrm{C}_{2}$ of thiadiazole), 170.412 ( $\mathrm{C}_{5}$ of thiadiazole); MS: $\mathrm{m} / \mathrm{z}(\mathrm{M}+)^{+} 358$.

Antibacterial activity: The antibacterial activity of the newly synthesized compounds, (3a-h) were assessed against $E$. coli by agar well diffusion method (Cappuccino et al., 1992). Mueller Hinton agar plates were prepared aseptically to get a thickness of 5-6 $\mathrm{mm}$. The plates were allowed to solidify and inverted to prevent condensate falling on the agar surface. The plates were dried at $37^{\circ} \mathrm{C}$ before inoculation. The sterile swab was dipped in the previously standardized inoculums and excess of inoculums was removed by pressing and rotating the swab firmly against the sides of the culture tube above the level of the liquid. The swab was then streaked all over the surface of the medium three times, rotating the plates through an 
angle of $60^{\circ}$ after each application. Finally, the swab was pressed round the edge of the agar surface. The inoculated medium was allowed to dry at room

\begin{tabular}{|ccc|}
\hline \multicolumn{3}{|c|}{ Table II } \\
\hline \multicolumn{3}{|c|}{ Antibacterial screening data } \\
\hline SL No. & Compound code & Zone of inhibition $(\mathrm{mm})$ \\
\hline 1 & $3 \mathrm{a}$ & 22 \\
2 & $3 \mathrm{~b}$ & 28 \\
3 & $3 \mathrm{c}$ & 22 \\
4 & $3 \mathrm{~d}$ & 24 \\
5 & $3 \mathrm{e}$ & 20 \\
6 & $3 \mathrm{f}$ & 23 \\
7 & $3 \mathrm{~g}$ & 21 \\
8 & $3 \mathrm{~h}$ & 28 \\
9 & Ciprofloxacin & 30 \\
\hline
\end{tabular}

temperature, with the lid closed. Cork borer was sterilized by using flame and well was made by using cork borer. By using micropipette, the test sample and standard were added into the well and were refrigerated for one hour to facilitate uniform diffusion of the drug. This was then incubated for 18-24 hours at $37^{\circ} \mathrm{C}$. The diameter of the zones of inhibition around the drugs were measured and compared with that of the standard. The antibacterial activity data is shown in Table II. All the synthesized compounds were tested for antibacterial activity against $E$. coli bacteria.

\section{Results and Discussion}

The virtual screening technique predicted that thiadiazole scaffold can possess excellent interaction profile with the target enzyme enoyl ACP reductase of E. coli. For improving the pharmacokinetic profile thiourea side chain was attached to the parent thiadiazole scaffold. The lead optimization technique showed that the thiourea substituted derivatives possessed excellent human intestinal absorption, plasma protein binding, $\log \mathrm{P}$ value with no signs of hepatotoxicity. Thus ADMEtox data evaluated through Accelerys Accord for Excel predicted that the designed leads are having good pharmacokinetic profile. The selected optimized leads on docking study revealed that there existed excellent interactions of the ligands with the enzyme. The ligands were interacting with the key amino acids Gly 93 and Tyr 158 through NAD (Figure 2). A hydrogen bonding network was seen between the ligand and Gly 93. Other prominent binding sites were Met 103, Leu195, Ala 196 and Ile 200. The highest binding affinity was possessed by $3 g$ and lowest by $3 b$ with a binding energy of -8.67 and $-6.56 \mathrm{Kcal} / \mathrm{mol}$ respectively. The renowned FabI inhibitor, triclosan is reported to show interactions with Gly 93, Met 103, Tyr 158, Leu195, Ala 196, Ile 200 through NAD. The probability for $3 \mathbf{h}$ to possess excellent anti E. coli activity was confirmed with PASS prediction which showed a Pa value of 0.810 . The PASS prediction has shown the predicted activity in the following order, i.e., $3 h>3 b>3 e>3 g>3 a>3 c>3 d>3 f$ order. The prediction showed that compound $3 \mathrm{~h}$ has the highest probability and $\mathbf{3 f}$ has the least probability of antibacterial activity. Most of the derivatives possessed a correlation with the PASS prediction.

The derivatives obtained through computational tools were synthesized. The title compounds, 1phenyl-[5substituted phenyl)-1,3,4-thiadiazol-2-yl]-3-thiourea (3a -h) were synthesized by the reaction of 2-amino-5substituted phenyl -1, 3, 4-thiadiazole (2a-h) with phenyl isothiocyanate and ethanolic potassium hydroxide. The amines, 2a-h were obtained by the oxidative cyclization of thiosemicarbazones with $\mathrm{FeCl}_{3}$ in presence of citric acid. The synthetic strategy is given in the Scheme 1. The spectral investigations revealed, the successful formation of the title compounds. The

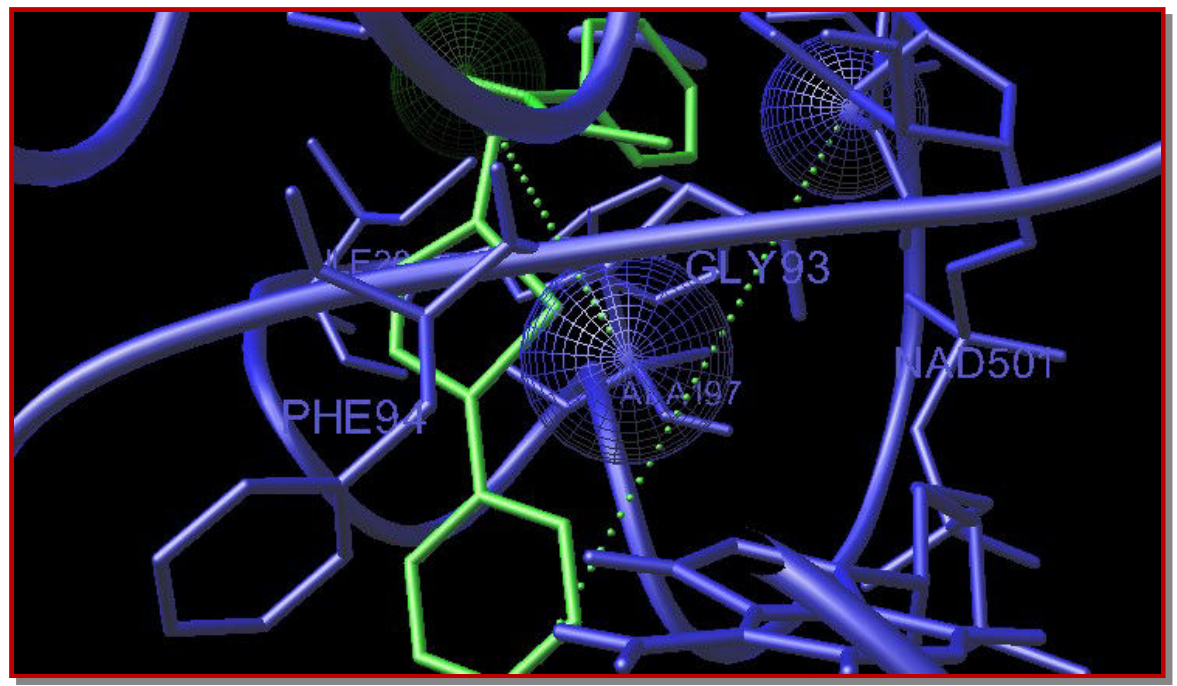

Figure 2: Snap shot representing the binding interactions of 3 hours binding with enoyl ACP reductase fab1 with the active residue GLY93 with two hydrogen bonds 


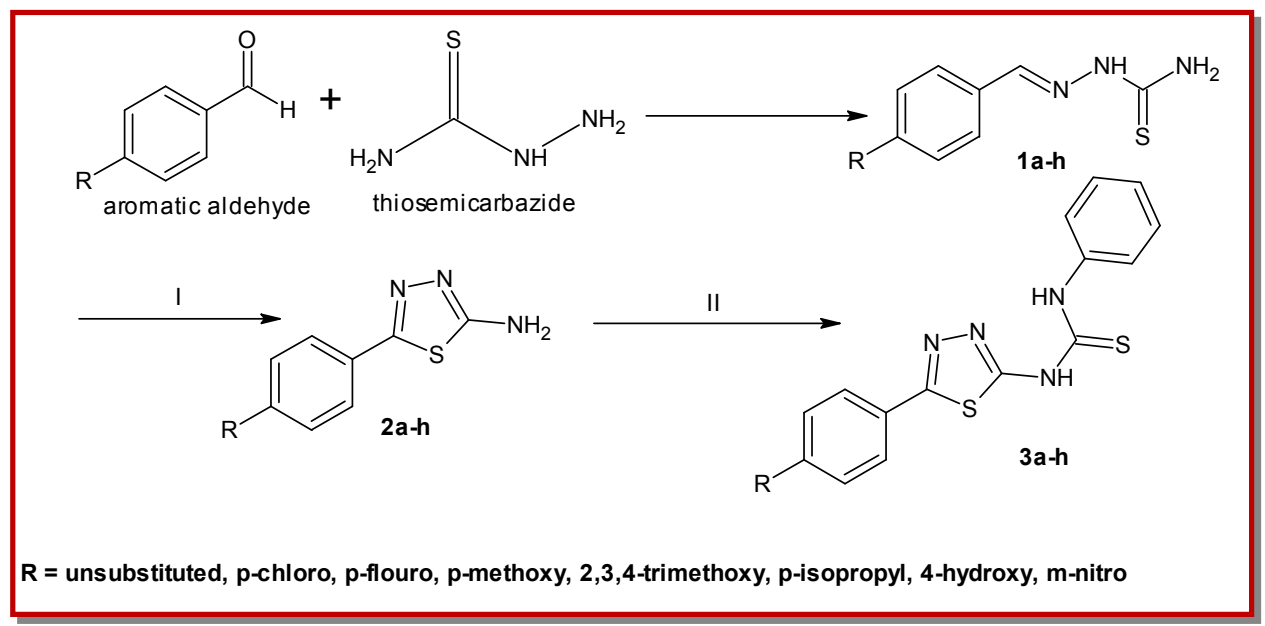

Scheme 1: Synthesis of thiadiazolyl thiourea

Reagents \& conditions: I: $\mathrm{FeCl}_{3}, 80-90^{\circ} \mathrm{C}, 45 \mathrm{~min}$; II: Phenyl isothiocyanate, $\mathrm{KOH}, 2 \mathrm{~h}$, reflux

presence of IR absorption bands at 3262.134 and 1591.32 corresponded to $\mathrm{NH}$ and thiadiazolyl $\mathrm{C}=\mathrm{N}$ respectively. Also, in the ${ }^{1} \mathrm{HNMR}$ spectrum, broad singlets at 10.491 and 9.241 corresponded for the NH groups in 3a. The multiplets ranging from 7.653-7.936 revealed the presence of aryl protons. The signals at 58.765, 121.234127.324, 162.375 and 172.310 obtained in ${ }^{13} \mathrm{CNMR}$ also revealed the successful formation of the title compounds. The molecular ion peak at 312 was corresponding with the molecular formula, $\mathrm{C}_{15} \mathrm{H}_{12} \mathrm{~N}_{4} \mathrm{~S}_{2}$ of $\mathbf{3 a}$.

The antibacterial results revealed that the derivatives, $\mathbf{3 b}$ and $\mathbf{3 h}$ showed a zone of inhibition of $28 \mathrm{~mm}$ when compared to the standard, ciprofloxacin $(30 \mathrm{~mm})$ at 250 $\mu \mathrm{g} / \mathrm{mL}$. Other derivatives also showed significant activity as predicted by the in silico studies. It can be assumed that the significant antibacterial potential exihibited by the above derivatives are due to the presence of electron with drawing groups like chloro and nitro groups.

To conclude with, the present research focussed on the design of enoyl ACP reductase inhibitors of E. coli has resulted in the development of novel thiourea linked 1,3,4-thiadiazole derivatives. The activity profile of the designed compounds indicated that there existed a significant correlation with the computational data. Thus the new 1,3,4-thiadiazolyl thiourea derivatives are excellent candidates in antibacterial drug discovery.

\section{References}

Arslan H, Duran N, Borekci G, Koray Ozer C, Akbay C. Antimicrobial activity of some thiourea derivatives and their nickel and copper complexes. Molecules 2009; 14: 519-
27.

Cappuccino JG, Sherman N. Microbiology: A laboratory manual. 3rd ed. New York, Benjamin Cummings Publishing Company, 1992, pp 51-66.

Bergler H, Wallner P, Ebeling A, Leitinger B, Fuchsbichler S, Aschauer H, Kollenz G, Högenauer G, Turnowsky F. Protein EnvM Is the NADH-dependent Enoyl-ACP Reductase (FabI) of Escherichia coli. J Biol Chem. 1994; 269: 5493-96.

Jatav V, Mishra P, Kashaw S, Stables JP. Synthesis and CNS depressant activity of some novel 3-[5-substituted1, 3, 4thiadiazole-2-yl]-2-styryl quinazoline-4(3H)-ones. Eur J Med Chem. 2008; 43: 135-41.

Kuo MR, Morbidoni HR, Alland D, Sneddon SF, et al. Targeting tuberculosis and malaria through inhibition of enoyl reductase: Compound activity and structural data. J Biol Chem. 2003; 278: 20851-59.

Poroikov VV, Filimonov DA. How to acquire new biological activities in old compounds by computer prediction? J Comput Aided Mol Des. 2002; 16: 819-24.

Richard JH, Charles OR. Enoyl-acyl carrier protein reductase (fabI) plays a determinant role in completing cycles of fatty acid elongation in Escherichia coli. J Biol Chem. 1995; 270: 26538-42.

Roujeinikova A, Levy CW, Rowsell S, Sedelnikova S, et al. Crystallographic analysis of Triclosan bound to Enoyl Reductase. J Mol Biol. 1999; 294: 527-35.

Sonia G, Ravi TK. Design, synthesis and antitubercular screening of certain novel thiadiazolyl pyrrolidine carboxamides as enoyl acp reductase inhibitors. Int J Pharm Pharm Sci. 2011; 3: 280-84.

Sonia G, Ravi TK. Oxadiazolo pyrrolidine carboxamides as enoyl-ACP reductase inhibitors: Design, synthesis and antitubercular activity screening. Med Chem Res. 2012; 22: 3428-33. 